\title{
Signature Pattern Recognition using Kohonen Network
}

\author{
Nadia Roosmalita Sari ${ }^{\text {a, }}$, *, Mohammad Zoqi Sarwani ${ }^{\text {b, }}$, \\ Yudha Alif Aulia ${ }^{\mathrm{c}, 3}$, Wayan Firdaus Mahmudy ${ }^{\mathrm{d}, 4}$ \\ a Department of Da'wah Management, Institut Agama Islam Negeri (IAIN) Tulungagung \\ Jl.Mayor Sujadi Timur No 46 Tulungagung, 66221, Indonesia \\ ${ }^{b}$ Department of Information Technology, Universitas Merdeka Pasuruan \\ Jl. Ir. H. Juanda No. 6, Pasuruan, 67129, Indonesia \\ ${ }^{c}$ Department of Information Technology, Universitas Jember \\ Jl. Kalimantan no 37, Jember, 68121, Indonesia \\ ${ }^{d}$ Department of Computer Science, Universitas Brawijaya \\ Jl. Veteran, Malang, 65145, Indonesia \\ ${ }^{1}$ nadiaroosmalitasari@gmail.com*; ${ }^{2}$ zoqi.sarwani@unmerpas.ac.id; ${ }^{3}$ yudha.alif7@gmail.com; ${ }^{4}$ wayanfm@ub.ac.id \\ * corresponding author
}

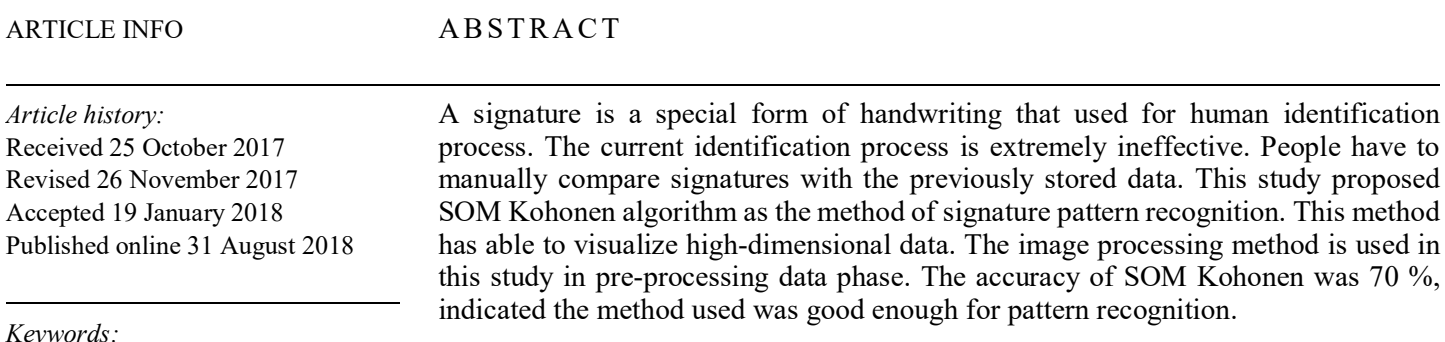
Signature Image processing This is an open access article under the CC BY-SA license (https://creativecommons.org/licenses/by-sa/4.0/).

\section{Introduction}

The manual process of signature identification is extremely ineffective. The being recognised signature is compared with a very large number of similar signatures. A computer based signature recognition could be ease the signature recognition process.

Various studies about signature recognition have been done. Backpropagation neural network is applied for the signature pattern recognition [1]. The results of this study produced an accuracy rate of $95 \%$ for the training data and $88 \%$ for the testing data. Another study used the moment invariant method and Euclidean distance for signature pattern recognition [2]. Moment invariant used to reduce the dimensions of the matrix. The result vector from invariant moment used as input data in the process of digital image recognition. Recognition method using Euclidean recognition measures the difference between the vectors. The result of this study indicated that the image recognizes all of the test data.

Many studies have investigated the signature pattern recognition. Akram, et al [3] summarized a study for offline signature recognition system using Artificial Neural Network (ANN). ANN has the ability to learn and generalize diversity and variation human signatures. ANN recognized signatures precisell [4]. In a particular case, ANN could be more accurate than other techniques such as SVM and PMT [5].

Chaudari, et al [6] has successfully examined the fuzzy min-max algorithm signature pattern recognition. Input was given in the form of digital images by using the writing pad, an optical scanner, or digital camera. The fuzzy min-max algorithm implemented to classify the signature patterns and this method is really nice applied to the ANN framework. The middle layer of ANN worked as a defuzzification neuron so that output can be classified correctly. Accuracy that was generated by using these methods amounted to $92 \%$. 
Another study that has been doing a study about signature pattern recognition was a research Deore and Handore study [7]. This study discussed about the offline signature pattern recognition where the figure was extracted using Discrete Wavelet Transform (DWT) and Principal Component Analysis (PCA).

Self Organizing Feature Map (SOM) Kohonen is a neural network method that is often used for pattern recognition. SOM Kohonen has been used as a method of pattern recognition in the form of handwritten in numbers. This study used the United Movement Invariant for extracting writing numbers as many as 500 data and SOM Kohonen method as a grouping method [8] with an accuracy of $98 \%$. In addition, sound processing for speaker recognition also has been examined by [9] The study also implemented SOM Kohonen as a method for sound processing. Accuracy generated by this study was $96 \%$. A similar study in sound recognition has been done by [9]. Linear Predictive Coding and SOM Kohonen have been used as a sound recognition method with an accuracy of $78 \%$ [8] used.

Based on some previous studies, this study proposes a neural network with SOM Kohonen models as a method for signature pattern recognition. In addition to SOM Kohonen method has been successfully implemented in some studies, SOM also has an advantage to visualize the highdimensional data into the simple geometric that has low dimension.

\section{Methods}

\section{A. Data collection and preprocessing}

The data used in this study in the form of signature pattern from 15 people with each person has signatures as much as 6 . Therefore, the total of signature sample is 90 signatures. Preprocessing performed during this phase to process the data in the form of a signature. Signatures that have been existed will be done a scanning process first. The next process was the processing to be performed the noise reduction, background elimination, and width normalization process.

In this scanning stage, the authentic signature used ink that has been obtained will do the scan process. Therefore, in this stage input was in the form of original signatures and the output resulted in the form of digital images. The results of the scanning process shown in Fig 1.

In the background elimination stage, background cropping in the area of data (signatures) was done. Background in the signature area located outside and besides to the signature object. Background cropping aims to equalize the entire area outside the object so that it has the same background color as shown in Fig. 2.

Noise is dots on the image which are not a part of the image, but also in the image for a reason [10]. Noise is something undesirable, regarded as the cause of the lack of detail of the signature object. Therefore, noise reduction used to eliminate objects that are outside the signature area thus making the object or image detail becomes better. The result of the noise reduction process shown in Fig. 3 . In image processing, normalization is a process that converts the pixel intensity range. Length and width dimensions of an object image are different. In this stage, the length and width of an object have to be recognized. In this stage, width normalization process was done by cutting the space between the edges of the image with the image object using Adobe Photoshop software. The outcome of this process is shown in Fig 4.

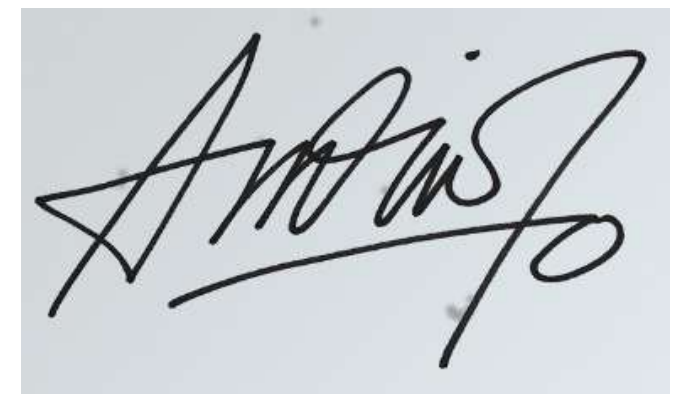

Fig. 1. Scanning process 


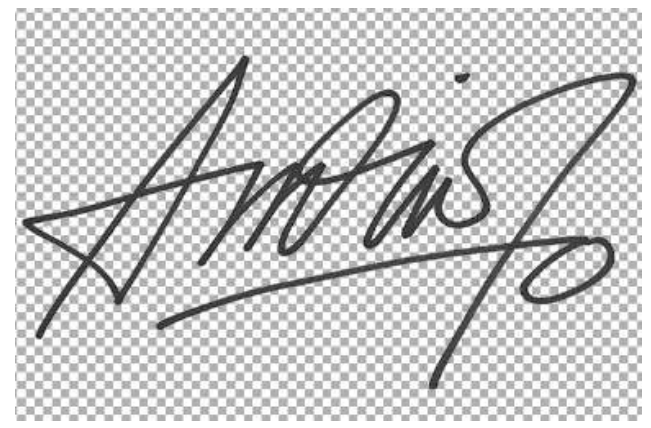

Fig. 2. Background elimination

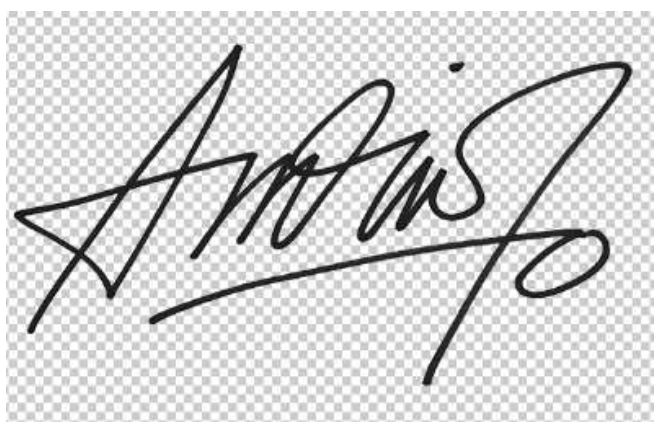

Fig. 3. The result of noise reduction process

Image processing is done to improve the image quality to be easily interpreted by a human or a computer for certain purposes, which in this study image processing used for the signature recognition. Hence, SOM Kohonen method implemented for image processing in the form of a signature. SOM Kohonen method requires some featured values that are extracted from the image.

Feature extraction process is divided into two stages, including the Global features and Grid Features. Global features are features that are common and easily obtained from the image. An example is the resolution of the image which includes the image length per pixel. In this study, the image resolution is required to be able to make the process of grid features. In this process, the feature was obtained by dividing the image into several parts. Each grid that has been divided then calculated the black pixel value to the white pixel, white pixels to the total pixels, and so on.

Fig. 5 is an example of a grid feature process result. In this discussion will look for the appropriate composition of the grid distribution. In general, the more the grid distribution, the greater the accuracy level, but requires memory and computation time that is greater. Therefore, it is needed to be done the grid testing of $3 \times 3,3 \times 4$ or $5 \times 5$. The experimental results are presented in Table 1 .

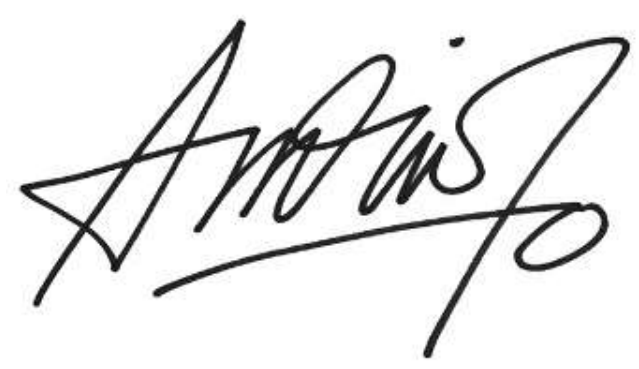

Fig. 4. The result of width normalization process 
Table 1. The result of feature extract on the data

\begin{tabular}{|c|c|c|c|c|c|c|}
\hline No & Name & Segment 1 & Segment 2 & $\ldots$ & Segment 224 & Segment 225 \\
\hline 1 & AАНJP & 255 & 255 & & 236.4941 & 168.0235 \\
\hline 2 & Alif & 255 & 255 & & 255 & 255 \\
\hline 3 & Dinna & 177.5214 & 177.4714 & & 255 & 255 \\
\hline 4 & Eko & 255 & 255 & & 255 & 254.5844 \\
\hline 5 & Evi & 255 & 255 & & 255 & 254.9846 \\
\hline 6 & Fadli & 255 & 255 & & 255 & 255 \\
\hline 7 & Ida & 254.9944 & 244.2278 & & 255 & 240.7111 \\
\hline 8 & Vivi & 255 & 255 & & 255 & 255 \\
\hline 9 & Wisnu & 255 & 255 & & 211.9375 & 200.2708 \\
\hline 10 & Asyrofa & 255 & 255 & & 255 & 255 \\
\hline
\end{tabular}

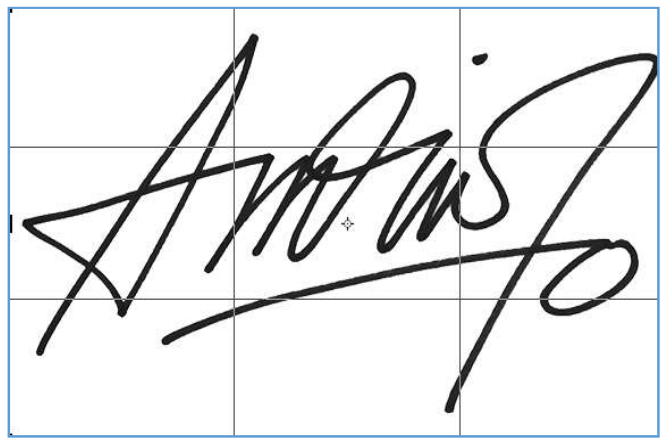

Fig. 5. Example of signature grid feature

\section{B. Signature Database}

For the training and testing data on the signature, recognition will be used the different data. The testing data and training data are treated equally. The signature is made in a sitting position and by using the same pen. The 90 signatures data is obtained from 15 people where each person is taken 6 signatures: 75 training data and 15 testing data. For example, signature data will undergo the feature values extracting process with $15 \times 15$ grids 225 segments. Because the grid feature distribution used was $15 \times 15$, then there will be 225 segments. The result of data extraction can be seen in Table 1 .

\section{Training Using Self Organizing Maps (SOM) Kohonen}

SOM method aims to cluster the input vectors based on how they are grouped according to the input characteristics. SOM combine the competitive layers process to the topology of input vectors included in the iteration process. SOM network consists of two layers, which are the input layer and the output layer [4]. Each neuron in the input layer is connected to each neuron in the output layer. Each neuron in the output layer represents the class of a given input. During the process self-arranging, cluster that has the weight vector which is the most appropriate to the input pattern (has the closest space) will be selected as the winner. Neuron becomes the winner along with its neighbour neurons would improve their weights. If we want to divide the data into k-cluster, then the competitive layer will consist of k neurons. Fig. 6 illustrates the architecture of SOM Kohonen and Fig. 7 shows the diagram of signature recognition process.

As shown in Fig. 1, as an example, that there are two input units (P1 and P2), which will be formed into 3 neuron clusters with the output layer (Y1, Y2, Y3). Furthermore, the neurons would improve their weights, as the Wij weight. In this case, the Wij weight contains the meaning a weight that connects jth neuron into the input layer toward the ith neuron output layer. 


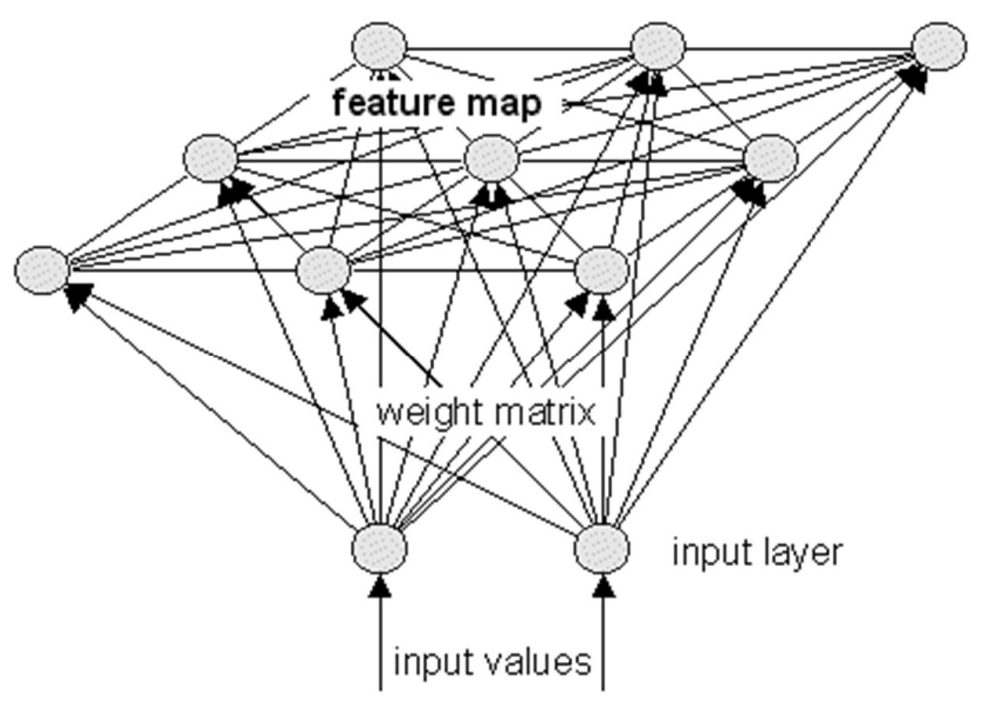

Fig. 6. SOM Kohonen architecture

Fig. 7. Flow diagram of signature recognition process in this study

\section{Results and Discussions}

Before entering into the SOM kohonen calculation phase, should be determined in advance which data would be used as training data and which data would be testing data. For the training data would be used 10 signature data that were the $1^{\text {st }}-10^{\text {th }}$ signature were going to be used. So, the amounts of training data are 75 signatures. Training data and testing data distribution were shown in Table 2 and Table 3 .

The training data process aims to find the suitable final weights and mapping to be used in the testing data process. Time needed to do the training as much as 75 data takes 3 hours to calculate SOM Kohonen. SOM Kohonen mapping results can be seen in Table 4. 
Table 2. Training data

\begin{tabular}{lllllll}
\hline No & Name & Segment 1 & Segment 2 & $\ldots$ & Segment 224 & Segment 225 \\
\hline 1 & AAHJP & 255 & 255 & $\ldots$ & 236.4941 & 168.0235 \\
2 & AAHJP & 255 & 255 & $\ldots$ & 164.9074 & 248.0185 \\
3 & AAHJP & 255 & 255 & $\ldots$ & 228.2039 & 255 \\
& & & & & & \\
$\ldots$ & $\ldots$ & $\ldots$ & $\ldots$ & $\ldots$ & $\ldots$ & $\ldots$ \\
73 & Asyrofa & 255 & 255 & & & 255 \\
74 & Asyrofa & 255 & 255 & $\ldots$ & 255 & 255 \\
75 & Asyrofa & 255 & 255 & $\ldots$ & 255 & 255 \\
\hline
\end{tabular}

Table 3. Testing data

\begin{tabular}{lllllll}
\hline No & Name & Segment 1 & Segment 2 & $\ldots$ & Segment 224 & Segment 225 \\
\hline 1 & AAHJP & 255 & 255 & $\ldots$ & 254.6538 & 206.0529 \\
2 & Alif & 255 & 255 & $\ldots$ & 245.8788 & 255 \\
3 & Dinna & 177.5214 & 177.4714 & $\ldots$ & 255 & 255 \\
4 & Eko & 255 & 255 & $\ldots$ & 255 & 254.5844 \\
5 & Evi & $\ldots$ & $\ldots$ & $\ldots$ & $\ldots$ & $\ldots$ \\
6 & Fadli & & & & & \\
7 & Ida & 254.9944 & 244.2278 & $\ldots$ & 255 & 240.7111 \\
8 & Vivi & 255 & 255 & $\ldots$ & 255 & 255 \\
9 & Wisnu & 255 & 255 & $\ldots$ & 211.9375 & 200.2708 \\
10 & Asyrofa & 255 & 255 & $\ldots$ & 255 & 255 \\
\hline
\end{tabular}

Table 4. The result of mapping data

\begin{tabular}{lllllll}
\hline Index & $\mathbf{1}$ & $\mathbf{2}$ & $\mathbf{3}$ & $\mathbf{4}$ & $\mathbf{5}$ & $\mathbf{6}$ \\
\hline 1 & AAHJP & Alif & Alif & AAHJP & Fadli & Fadli \\
2 & Wisnu & AAHJP & Eko & Alif & Dinna & Alif \\
3 & Fadli & Vivin & Asyrofa & Dinna & Eko & Jaya \\
4 & Vivin & Hilman & Vivin & Dinna & Bagus & Eko \\
5 & Ida & Evi & Evi & Evi & Jaya & Eko \\
6 & Ida & Ida & Eko & Agung & Evi & Vivi \\
\hline
\end{tabular}

In this study, the testing data was done after the result of the weight and mapping obtained in the previous data training. It was obtained based on the training data result. The testing data used in this study were 10 signatures with each different signature. These data used as input data. While the output data on the testing stage were in the form of true or false condition, the testing data was carried out in a minute. Table 1 shows the result of testing data. Based on Table 5, the results of data analysis recognizable signature or the correct data obtained as much as 7 data. While the remaining 3 are the signature data that are not recognized or wrong.

After the testing data process, the accuracy calculation using Equation 1 was done. The accuracy calculation obtained from the amount of the correct data divided by the total of data used, then multiplied by $100 \%$.

$$
\text { Accuracy }=\frac{\text { The amount of the correct data }}{\text { Total data }} * 100 \%
$$

The accuracy obtained by calculation in Equation 1 was $70 \%$. Based on the result of accuracy, the application of SOM Kohonen method was good enough to be used as a method for signature pattern recognition. 
Table 5. The results of testing data

\begin{tabular}{lllll}
\hline No & Name & Input & Output & Result \\
\hline 1 & AAHJP & AAHJP & AAHJP & True \\
2 & Alif & Alif & Alif & False \\
3 & Dina & Dina & Asyrofa & True \\
4 & Eko & Eko & Eko & True \\
5 & Evi & Evi & Evi & True \\
6 & Fadli & Fadli & Fadli & True \\
7 & Ida & Ida & Ida & True \\
8 & Vivi & Vivi & Vivi & True \\
9 & Wisnu & Wisnu & Ida & False \\
10 & Asyrofa & Asyrofa & Vivi & False \\
\hline
\end{tabular}

\section{Conclusion}

SOM Kohonen network can analyse 7 signature data from 10 data correctly, so that gives a result of accuracy that is $70 \%$. This accuracy has not perfectly reached because it is influenced by many factors, which are the determination of the initial weight dimensions that still random and the grid determination on data. The algorithm performed an introduction to the more complex data, e.g. signature data that are rotated. For further study, it will be performed the weight modification by optimizing the weight, using evolutionary algorithms to improve the accuracy.

\section{References}

[1] A. Hidayatno, R. R. Isnanto, and D. K. W. Buana, "Identifikasi Tanda-Tangan Menggunakan Jaringan Saraf Tiruan Perambatan-Balik (Backpropagation)," J. Teknol. IST AKPRIND, vol. 1, no. 2, 2008.

[2] David and S. KOSASI, "Penerapan Algoritma Jaringan Saraf Tiruan Backpropagation untuk Pengenalan Pola Tanda Tangan," Teknologi, vol. 6, no. 2, 2013.

[3] M. Akram, R. Qasim, and M. A. Amin, "A comparative study of signature recognition problem using statistical features and artificial neural networks," in 2012 International Conference on Informatics, Electronics \& Vision (ICIEV), 2012, pp. 925-929.

[4] A. Karouni, B. Daya, and S. Bahlak, "Offline signature recognition using neural networks approach," Procedia Comput. Sci., vol. 3, pp. 155-161, 2011.

[5] I. Bhattacharya, P. Ghosh, and S. Biswas, "Offline Signature Verification Using Pixel Matching Technique," Procedia Technol., vol. 10, pp. 970-977, 2013.

[6] B. M. Chaudhari, A. A. Barhate, and A. A. Bhole, "Signature recognition using fuzzy min-max neural network," in 2009 International Conference on Control, Automation, Communication and Energy Conservation, 2009, pp. 1-7.

[7] M. R. Deore and S. M. Handore, "Offline signature recognition: Artificial neural network approach," in 2015 International Conference on Communications and Signal Processing (ICCSP), 2015, pp. 1708-1712.

[8] G. F. Fitriana and S. Samsuryadi, "Penggunaan United Moment Invariant dan Self Organizing Maps untuk Pengenalan Tulisan Tangan Angka," J. Generic, vol. 10, no. 1, pp. 398-404, 2015.

[9] P. Sahayu and G. Fitriana, "Pengenalan Suara Menggunakan Linear Predictive Coding dan Self Organizing Maps," Annu. Res. Semin., vol. 1, no. 1, pp. 21-22, 2015.

[10] E. Özgündüz, T. Şentürk, and M. E. Karslıgil, "Off-line signature verification and recognition by Support Vector Machine," in 2005 13th European Signal Processing Conference, 2005, pp. 1-4. 